\title{
Effects of the irregularity in the cross sectional distribution of velocity on the 1D shallow-water model
}

\author{
J. Burguete ${ }^{1}$, P. García-Navarro ${ }^{2}$ and J. Murillo ${ }^{2}$ \\ ${ }^{1}$ Suelo y Agua. Estación Experimental Aula Dei. CSIC. Zaragoza. Spain \\ ${ }^{2}$ Fluid Mechanics. CPS. Universidad de Zaragoza. Zaragoza. Spain
}

In this work, a decomposition of the channel cross section in subsections is performed to improve the 1D shallow-water simulation of unsteady open channel flows in cases of distorted cross sectional shapes. Some test cases with measured data are used to validate the quality of the approaches and a natural river is used to illustrate the effects due to the cross sections irregularity.

\section{INTRODUCTION}

To model friction in 1D shallow-water, empirical or semi-empirical methods like Gauckler-Manning have traditionally been applied. In cases of channel or river flow with overbank sections as well as those with non-uniform cross section bed roughness, the traditional hypothesis of uniform velocity is unrealistic. It is not obvious what is the correct form to incorporate a cross sectional variability of the frictional coefficient in 1D models. It becomes necessary to perform a decomposition of the channel cross section in subsections as, for instance, suggested in (Chow 1959; Knight 2006; Cao et al. 2006; Burguete et al. 2007). This procedure is based on the assumption of a single cross sectional energy slope. We seek a model less refined than (Shiono et al. 1999), who model lateral exchange of momentum requiring the solution of a differential equation in the transversal direction and therefore becomes excessively complex for our purpose. The lateral exchange of momentum is neglected in our approach. The main hypothesis will be that the wetted cross section is much wider than deep and our simplification will be supported by experimental evidence (MacGahey et al. 2006) that the lateral exchange of momentum effects and secondary flows have a relative magnitude smaller than boundary friction effects in most rivers. A laboratory channel and a gauge section in a river, both cases with measured data, are used to validate the quality of the approaches. Finally, the model is applied in a natural river to illustrate the effects due to the cross sections irregularity.

\section{FRICTION MODEL}

The 1D momentum conservation equation in open channel flow models can be expressed as:

$$
\frac{\partial Q}{\partial t}+\frac{\partial}{\partial x}\left(\frac{\beta Q^{2}}{A}+g I_{1}\right)=g\left[I_{2}+A\left(S_{0}-S_{f}\right)\right]
$$

where $A$ is the wetted cross section, $Q$ the discharge, $g$ the gravitational acceleration, $S_{0}$ the main bed slope, $S_{f}$ the friction stress over the solid surface in the channel reach, $\beta$ is a coefficient that appears as a result of the assumption of variable velocity in the cross section:

$$
\beta=\frac{A}{Q^{2}} \int_{A} v_{x}^{2} d A
$$

with $v_{x}=v_{x}(x, y, z, t)$ the $x$ component of the local point flow velocity, and $I_{1}, I_{2}$ pressure forces integrals (Chow 1959). 
In the empirical Gauckler-Manning model, the friction slope $S_{f}$ is:

$$
S_{f}=\frac{n^{2}|Q| Q}{R^{4 / 3}}
$$

with $R=A / P$ the hydraulic radius, $P$ the wetted perimeter and $n$ the Gauckler-Manning coefficient. This model is only valid in cases of uniform flow velocity distribution in a cross section. In irregular sections or compound channels, the velocity cannot be considered uniform in a cross section. In these cases a constant slope model can be used (Burguete et al. 2007). In this case:

$$
U=\frac{ \pm \sqrt{\left|S_{f}\right|} h^{2 / 3}}{n} \Rightarrow Q=\int_{A} U h d y= \pm \sqrt{\left|S_{f}\right|} \int_{A} \frac{h^{5 / 3}}{n} d y \Rightarrow S_{f}=\frac{|Q| Q}{\left(\int_{A} \frac{h^{5 / 3}}{n} d y\right)^{2}}
$$

with $h$ the local water depth, $U$ the depth-averaged water velocity and $y$ the transversal coordinate. This model also enables an estimation of the cross sectional momentum distribution $\beta$ parameter:

$$
\beta=\frac{A \int_{A} U^{2} h d y}{Q^{2}}=\frac{A S_{f}}{|Q| Q} \int_{A} \frac{h^{7 / 3}}{n^{2}} d y
$$

\section{EXAMPLES}

\subsection{Experimental FCF series}

The experimental data from 50 cases measured in a smooth compound channel laboratory setup from the FCF series of the University of Birmingham (Knight 2004) have been used as additional validation. Figure 1 is a sketch of the channel cross section geometry. We shall to define $U_{H}$ as the depth averaged velocity and $H$ the

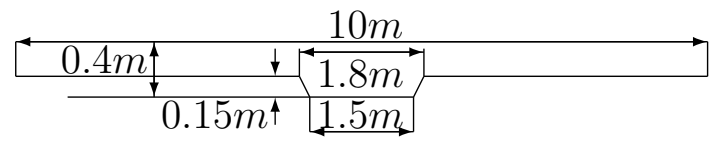

Figure 1: Cross section geometry of the serie I of the FCF channels.

maximum depth, both at the canal axis. Figure 2(a) is a plot of $U$ versus $y$ for this case. The velocity values predicted by the model agree with the observed values within a $20 \%$ of error. Finally, Figure 2(b) displays the variation of $\beta$ with $H$ both as predicted by the model and as estimated from the measurements. Again, the models provide a reasonable prediction.

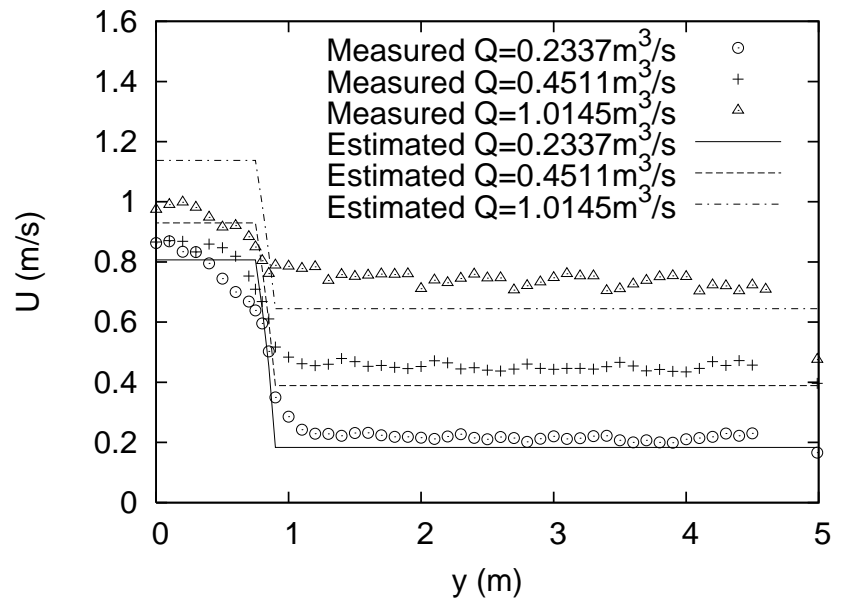

(a)

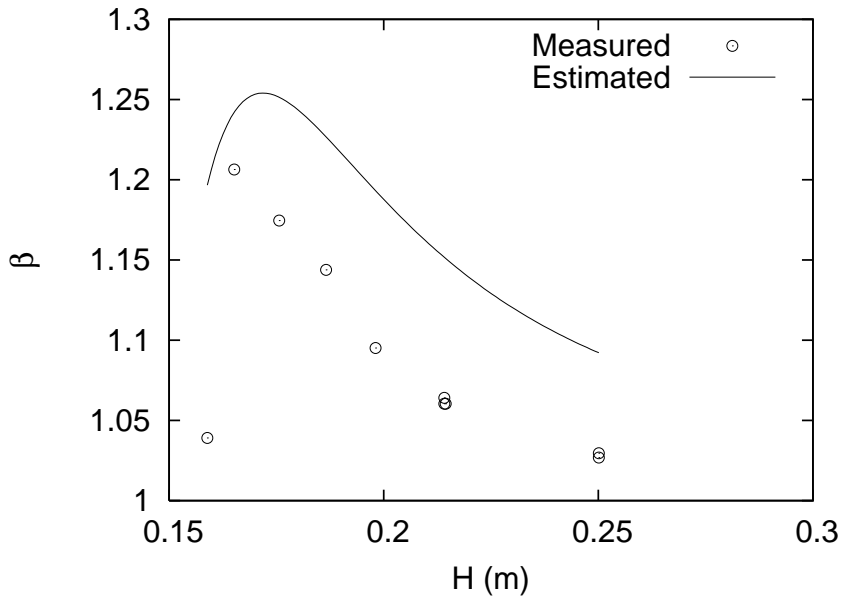

(b)

Figure 2: (a) Depth-averaged water velocity, (b) comparison of the $\beta$ parameter versus depth both measured and predicted by model in the serie I of the FCF channel. 


\subsection{Experimental river flow velocity data}

A set of more than 200 water velocity data, measured at a gauging station by the Statistics and Gauging Service of the Ebro River Water Authority (Confederación Hidrográfica del Ebro, Spain), have been used in the second case presented. The data were collected at an irregular section of the Ebro River by means of a probe located at different depths and transverse position within the section, under three different water discharge conditions (26, 68 and $147 \mathrm{~m}^{3} / \mathrm{s}$ ). None of the discharges was extraordinary so that water was always in the main channel. The hypothesis made was that the bed river roughness is approximately the same all over the cross section.

Figure 3(a) represents the comparison of the measured and predicted $U$ velocity values along the cross section for the three discharges. The model prediction is close to the experimental data. Finally, Figure 3(b) displays the estimate of the $\beta$ value from the measured data as function of $H$ for the three discharges. It is compared with the predictions of this parameters provided by the models. Despite the good agreement of the velocity profiles supplied by the model they slightly underestimate the value of $\beta$. This can be explained by the simplification made assuming that there is a uniform value of roughness coefficient in the cross section.

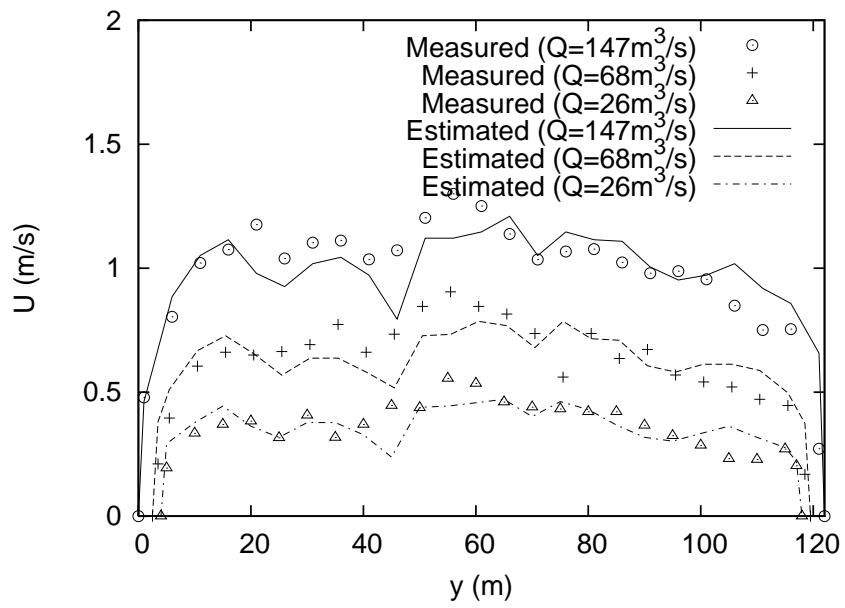

(a)

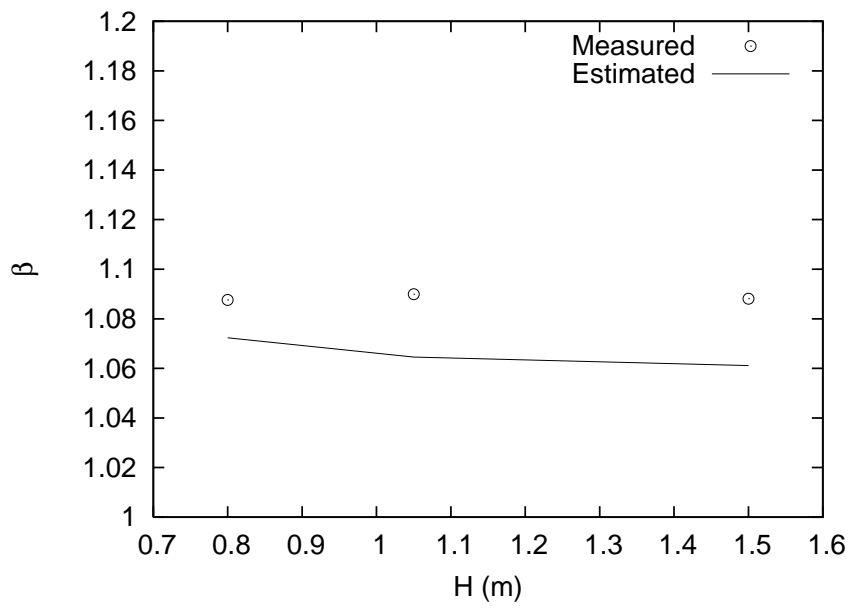

(b)

Figure 3: (a) Depth-averaged water velocity, (b) comparison of $\beta$ coefficient versus depth both measured and predicted by model in the Ebro River cross section.

\subsection{Friction models in typical river cross sections}

The model predictions of the $\beta$ values at four typical Ebro River cross sections will be next compared. The cross sections are represented in Figure 4. The value of the roughness coefficient used is $n=0.03 \mathrm{sm}^{-1 / 3}$, taken from

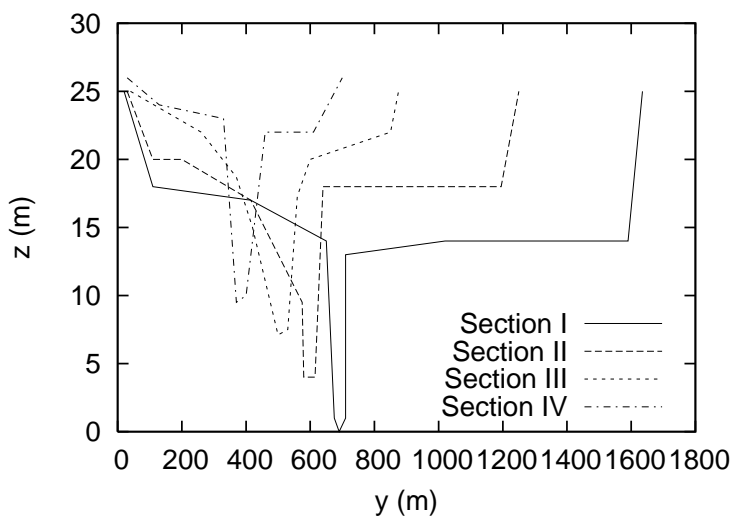

Figure 4: Cross sectional form of four typical Ebro River sections.

the literature (Chow 1959). Figure 5(a) shows the plot of the $\beta$ values predictions at the four river sections. The value reached by this coefficient, as obtained with the friction model, is close to 2 in some cases, indicating that the basic approximation of this coefficient by 1 is not realistic and can lead to inaccurate models. Having stated the acceptable validity of the model predictions under laboratory conditions, this is a good example that provides an evidence of the values of $\beta$ in realistic conditions. In Figure 5(b) $S_{f}$ is plotted versus $H$, assuming 
a constant velocity $U=1 \mathrm{~m} / \mathrm{s}$ according to the simple classical form, equation (3), and the $S_{f}$ constant model, equation (4). Apart from the great discrepancy observed when the main channel is overflown, it can also be observed that the constant friction slope model predicts rather lower friction values even at low discharges.

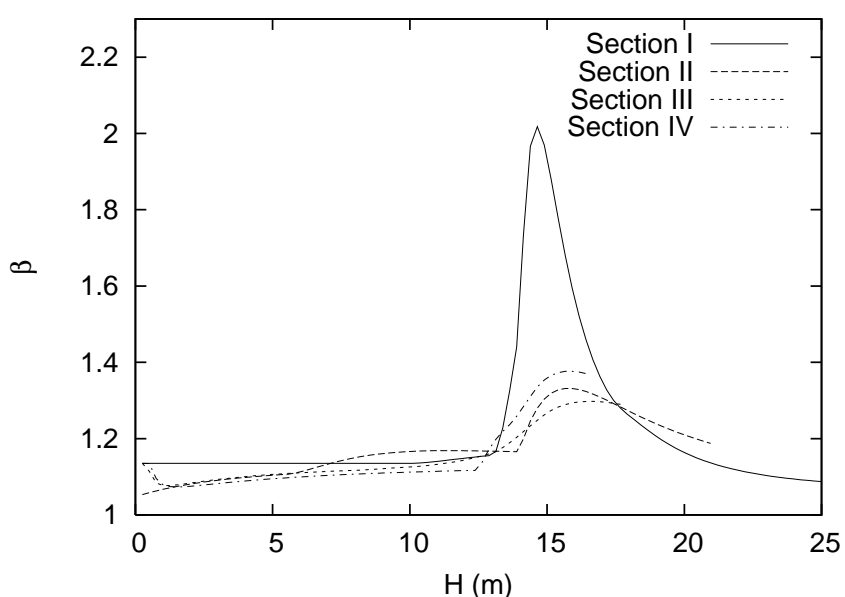

(a)

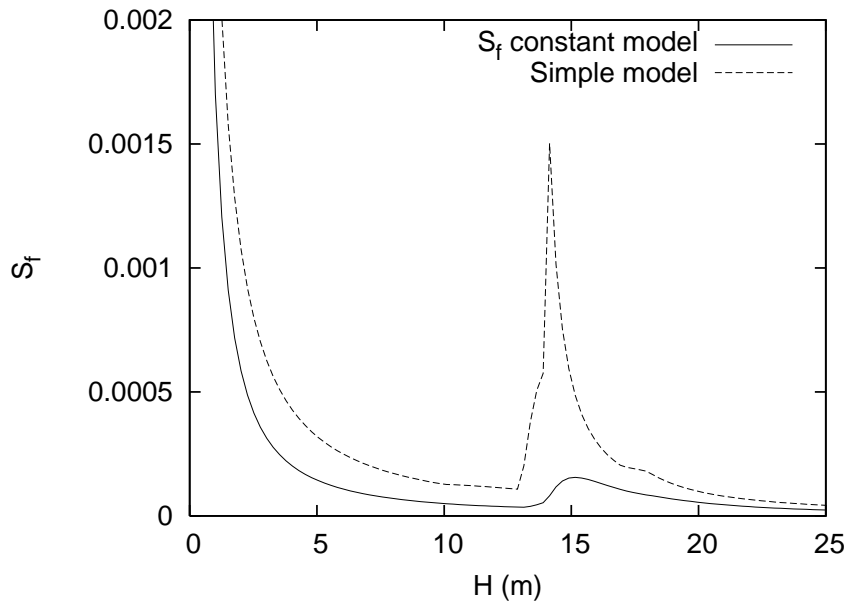

(b)

Figure 5: (a) Estimated values of the $\beta$ coefficient in the four sections, (b) comparison of the $S_{f}$ in the section I by simple (3) and constant friction slope (4) models, both as a function of the water depth.

\section{CONCLUSIONS}

In irregular or compound cross sections, a hypothesis has been analysed for the cross sectional velocity distribution based on the constant friction slope across the wetted cross section. The experimental validation has been helpful to show the agreement with the predictions of the model. The cross sectional velocity distributions predicted can also be used to estimate the factor $\beta$. Our calculations show that this factor must be evaluated since it can reach values much higher than the usually assumed value of $\beta=1$ in cases of flood over a floodplain. Furthermore, it has been proved that the friction values are smaller when considering an irregular cross sectional velocity distribution than those predicted by the simpler uniform velocity assumption. Therefore, and taking into account that most of the available friction coefficient values in the literature derive from the simple model, it can be stated that when using both the constant slope model in 1D problems or in 2D models the value of the roughness coefficient must be increased if an agreement with the simple 1D model is sought.

\section{References}

Burguete, J., P. García-Navarro, and J. Murillo (2007). Friction term discretization and limitation to preserve stability and conservation in the 1d shallow-water model: application to unsteady irrigation and river flow. ASCE Journal of Hydraulic Engineering in press.

Cao, Z., J. Meng, G. Pender, and S. Wallis (2006). Flow resistance and momentum flux in compound open channels. ASCE Journal of Hydraulic Engineering 132(12), 1272-1282.

Chow, V. T. (1959). Open channel hydraulics. New York: McGraw Hill.

Knight, D. W. (2004). FCF Series, flow database at the University of Birmingham, <www.flowdata.bham. ac.uk> (Downloaded Jan. 22, 2007).

Knight, D. W. (2006). River flood hydraulics: validation issues in one-dimensional flood routing models. London: Taylor \& Francis.

MacGahey, C., P. G. Samuels, and D. W. Knight (2006). A practical approach to estimating the flow capacity of rivers - application and analysis. Lisboa. River Flow: Taylor \& Francis.

Shiono, K., Y. Muto, D. W. Knight, and A. F. L. Hyde (1999). Energy losses due to secondary flow and turbulence in meandering channels with overbank flow. Journal of Hydraulic Research 37(5), 641-664. 